\title{
Zinc Chloride Protects against Streptozotocin-Induced Diabetic Nephropathy in Rats
}

\author{
Waleed H. Almalki ${ }^{*}$, El-Shaimaa A. Arafa' ${ }^{2}$, Amal Y. Abdallah', Amal M. Mahfoz ${ }^{3,4}$, \\ Afaf 0. Osman",5, Hekma A. Abd El-Latif6, Imran Shahid ${ }^{1}$ \\ ${ }^{1}$ Department of Pharmacology and Toxicology, Faculty of Pharmacy, Umm Al-Qura University, Mecca, \\ Saudi Arabia \\ ${ }^{2}$ Department of Pharmacology and Toxicology, Faculty of Pharmacy, Beni-Suef University, Beni-Suef, Egypt \\ ${ }^{3}$ Department of Pharmacology and Toxicology, Faculty of Medicine, Umm Al-Qura University, Mecca, \\ Saudi Arabia \\ ${ }^{4}$ National Organization for Drug Control and Research (NODCAR), Giza, Egypt \\ ${ }^{5}$ Department of Biochemistry, Faculty of Medicine, Umm Al-Qura University, Al Qunfudhah, Saudi Arabia \\ ${ }^{6}$ Department of Pharmacology and Toxicology, Faculty of Pharmacy, Cairo University, Cairo, Egypt \\ Email: *whmalki@uqu.edu.sa, aomosman@uqu.edu.sa, aymahmoud@uqu.edu.sa, \\ elshimaa.arafa@pharm.bsu.edu.eg, abdeltawabhekma@yahoo.co.uk,amal_ph84@yahoo.com, \\ iyshahid@uqu.edu.sa
}

Received 12 July 2016; accepted 26 August 2016; published 29 August 2016

Copyright (C) 2016 by authors and Scientific Research Publishing Inc.

This work is licensed under the Creative Commons Attribution International License (CC BY). http://creativecommons.org/licenses/by/4.0/

(c) (i) Open Access

\begin{abstract}
Diabetes mellitus (DM) is a health problem affecting millions of individuals worldwide. Diabetic nephropathy (DN), as a significant complication of DM, has become the most common cause of endstage renal failure. Oxidative stress constitutes the key and common events in the pathogenesis of DN and antioxidants may play a beneficial role in its prevention. This study was conducted to investigate the effect of Zinc Chloride on streptozotocin-induced diabetic nephropathy in rats compared to Gliclazide, a reference antidiabetic agent. Results showed that Zinc Chloride was able to control STZ-induced DN in rats as it normalized the elevated blood pressure, the increased insulin release, and the decreased blood glucose level. Zinc Chloride also improved kidney function as determined by the restoration of blood urea and creatinine level. Finally, Zinc Chloride was able to boost the antioxidant defenses of the kidney by increasing the reduced glutathione content and decreasing lipid peroxides content in addition to significantly decreasing kidney nitric oxide content compared to diabetic control rats. These results suggest that exposure to Zinc Chloride can protect from diabetic nephropathy and can be used as an adjuvant approach to treatment and prevention of renal damage.
\end{abstract}

\footnotetext{
"Corresponding author.
}

How to cite this paper: Almalki, W.H., Arafa, E.-S.A., Abdallah, A.Y., Mahfoz, A.M., Osman, A.O., El-Latif, H.A.A. and Shahid, I. (2016) Zinc Chloride Protects against Streptozotocin-Induced Diabetic Nephropathy in Rats. Pharmacology \& Pharmacy, 7, 331-342. http://dx.doi.org/10.4236/pp.2016.78041 


\section{Keywords}

\section{Zinc Chloride, Oxidative Stress, Streptozotocin, Diabetes, Nephropathy}

\section{Introduction}

Diabetes is a serious health hazard currently affecting more than 220 million people worldwide and expected to affect 400 million by 2030 [1] [2]. Diabetes being a metabolic disorder produces in the long run, cell dysfunction in almost all organs in the body. The most serious complications of diabetes are coronary artery disease, nephropathy, retinopathy, and neuropathy. Oxidative stress is thought to play a major role in the development of most of these complications [3]-[5]. Oxidative stress may occur when antioxidant mechanisms are not working properly as in dietary deficiencies of vitamin E, vitamin C or the essential elements like selenium, zinc, and manganese among others. The later elements are essential components of the antioxidant enzymes glutathione peroxidase, superoxide dismutase and catalase [6]-[8]. Another important cause of oxidative stress is the excessive endogenous production of free radicals by diseases progression as in diabetes mellitus and cancer [6].

Diabetic nephropathy is a severe, chronic complication of diabetes mellitus, and it is the leading cause of end-stage renal failure in diabetic patients [9]. It results from the combined effects of various genetic and environmental factors. Elevated glucose and cholesterol levels, increased production of inflammatory cytokines are the predisposing factors for the progression of renal damage in diabetic nephropathy [10]. Elevated glucose levels were recognized as a pathogenic factor of chronic diabetic complications by generating reactive oxygen species (ROS) and attenuating the antioxidative machinery via glycation of the antioxidant enzymes [11]. The major ROS sources in the diabetic nephropathy were: autoxidation of glucose, the activation of polyol pathways, mitochondrial respiratory chain deficiencies, xanthine oxidase activity, $\mathrm{NAD}(\mathrm{P}) \mathrm{H}$ oxidase, advanced glycation end products (AGEs) and nitric oxide synthase (NOS) [12]. The increased oxidative stress leads to injuries of the glomeruli [13], tubular interstitial tissue [14] and vasculature [15]. It is implicated in the mesangial expansion of extracellular matrix, and results in increased glomerular filtration rate, urine protein excretion, progression of glomerular sclerosis and tubular interstitial fibrosis [16]-[18]. Thus antioxidative therapy may be an effective way to treat diabetic nephropathy [19]. In addition, agents having both antioxidant and hypoglycemic effects might have promising protective actions against diabetic nephropathy [20].

Zinc is an essential component of numerous proteins which play crucial roles in growth and development. It showed potent antioxidant and anti-inflammatory properties and was involved in the defense against oxidative stress [21] [22]. Diabetic patients often suffer from Zinc deficiency at the late stage, particularly in the patients whose glucose was poorly controlled [23]-[26]. In addition, zinc has been reported to exert antidiabetic effects in various experimental models [27]. Thus, it seems that Zinc is a proper mineral supplement in diabetic patients. The STZ-diabetic animal model was selected for this study as it induces nephropathy analogous to the early stages of clinical nephropathy [28] [29]. STZ displayed pancreatic beta-cell toxicity via different mechanisms including targeted uptake of STZ in beta cells by Glut2 receptors [30] and increased oxidative stress due to NO release and ROS production [31] [32].

The aim of the present study was to examine the effect of Zinc Chloride treatment on the progression of renal biochemical changes in STZ-induced diabetic rats. It was designed to determine whether therapeutic intervention with Zinc Chloride would prevent the onset and progression of renal complications or not as compared with Gliclazide, a reference antidiabetic. Gliclazide has been reported to protect against renal damage in glomeruli and the proximal and distal tubules in a diabetic rat model [33].

\section{Material and Methods}

\subsection{Animals}

Adult Wistar rats of either sex weighing 160 - 200 g were obtained from the animal house of King Abdulaziz University, Jeddah, Saudi Arabia. The animals were maintained under controlled laboratory conditions (temperature $\left(22^{\circ} \mathrm{C} \pm 1{ }^{\circ} \mathrm{C}\right)$, humidity ( $\left.60 \% \pm 5 \%\right)$, and a $12 / 12 \mathrm{~h} \mathrm{light/dark} \mathrm{cycle).}$

The experimental protocol was approved by the Animal Care and Use Committee of the University of Umm 
Al-Qura, KSA. Maximum effort was made to minimize animal suffering.

\subsection{Chemicals}

Streptozotocin (STZ) was purchased from Sigma-Aldrich (USA). Zinc Chloride was purchased from Qualikems (India). Reduced glutathione and lipid peroxides detection kits were purchased from Biodiagnostic (Egypt). Creatinine, urea, and albumin assay kits were purchased from Salucea, Dutch technology in life science (Netherlands). Nitric oxide colorimetric assay kit was purchased from Biovision (USA). Other used chemicals were of the highest analytical grade.

\subsection{Experimental Design and Treatment Protocol}

Diabetes was induced by intraperitoneal injection of STZ dissolved in $0.1 \mathrm{~mol} / \mathrm{L}$ sodium citrate buffer $(\mathrm{pH}=4.0)$ at a dose of $65 \mathrm{mg} / \mathrm{kg}$ body weight [10]. Fasting, tail-vein, blood glucose was measured three days after injection by using one touch glucometer (Yi Cheng, BeiJing, China), and rats that have a glucose level over $250 \mathrm{mg} / \mathrm{dl}$ were considered diabetic [34]. The normal control group received citrate buffer.

Diabetic rats were divided into 3 groups of 8 animals each. The first group served as diabetic control. The second group rats received a daily IP injection of $5 \mathrm{mg} / \mathrm{kg}$ Zinc Chloride for one month. The third group, rats received a daily IP injection of $10 \mathrm{mg} / \mathrm{kg}$ gliclazide for one month [35].

\subsection{Tissue Collection and Preparation}

On the $30^{\text {th }}$ day, rats were fasted overnight. Blood pressure and heart rate were measured using Tail cuff (9), then rats were sacrificed under light ether anesthesia. The blood samples were collected, centrifuged and serum was kept frozen for measuring: glucose, insulin, urea, albumin, and creatinine.

The two kidneys were isolated and kept frozen for measuring: malondialdehyde (MDA), reduced glutathione (GSH) and nitric oxide $\left(\mathrm{NO}_{\mathrm{x}}\right)$.

\subsection{Determination of Blood Pressure and Heart Rate}

Rats blood pressure and heart rate were assessed by using CODA ${ }^{\mathrm{TM}}$ (Kent Scientific, Torrington, CT, USA). Readings were taken for 20 cycles from each rat. Systolic and diastolic blood pressure were expressed as mmHg. Heart rate was expressed as beat/min.

\subsection{Determination of Mean Arterial Pressure}

Mean arterial pressure (MAP), is defined as the average pressure in arteries during one cardiac cycle. It is considered a better indicator of perfusion to vital organs than systolic blood pressure (SBP). MAP was calculated using the following equation and expressed as $\mathrm{mmHg}$

$$
\text { MAP }=[(2 \times \text { diastolic })+\text { systolic }] / 3
$$

\subsection{Determination of Blood Glucose Level}

Fasting serum glucose level was determined colorimetrically according to the method of Trinder (1969) using a commercial reagent kit.

\subsection{Determination of Blood Insulin Level}

Fasting serum insulin level was determined using a commercial ELISA kit (Li KaShing Faculty of Medicine, The University of Hong Kong, AIS).

\subsection{Determination of Kidney Function}

Serum creatinine, serum urea, and serum albumin levels were determined as previously described using commercial reagent kits (Salucea, Dutch technology in life science, Netherlands). 


\subsection{Determination of Kidney Lipid Peroxides Content}

Lipid peroxidation was determined as described previously by [36] and according to manufacturer procedures of the assay kit (Biodiagnostic) and were expressed as mg \%, thiobarbituric acid reactive substances (TBARS) content, estimated as malondialdehyde (MDA). The absorbance was measured at $520 \mathrm{~nm}$ and expressed as $\mathrm{mmol} / \mathrm{g}$. tissue.

\subsection{Determination of Kidney GSH Content}

Reduced glutathione (GSH) was determined as described previously by [37] and the content was estimated following manufacturer's procedure of the assay kit (Biodiagnostic). The method is based on the reduction of 5,5' dithiobis (2-nitrobenzoic acid) (DTNB) with glutathione to produce a yellow compound; the reduced chromogen is directly proportional to GSH concentration, and the absorbance was measured at $405 \mathrm{~nm}$ and expressed as $\mathrm{mmol} / \mathrm{g}$. tissue.

\subsection{Determination of Kidney Total Nitrate and Nitrite Contents}

Total nitrate/nitrite (NOx) contents were measured using Nitric Oxide $\left(\mathrm{NO}_{2}^{-} / \mathrm{NO}_{3}^{-}\right)$Colorimetric Assay kit (Biovision) according to manufacturer procedures. The method is based on the enzymatic conversion of nitrate to nitrite, utilizing Nitrate Reductase, followed by Griess reagent and the formation of a deep purple azo compound which absorbs visible light at $540 \mathrm{~nm}$. The amount of the azo chromophore accurately reflects nitric oxide amount in the samples. Results were expressed as nmol/g. tissue.

\subsection{Statistical Analysis}

The data were presented as means \pm standard error (S.E.). Statistical analysis was performed using SPSS statistical software (version 16). Comparisons between different groups were carried out using one-way analysis of variance (ANOVA) followed by Tukey-Kramer multiple comparisons test. The Differences were considered statistically significant at $\mathrm{p}<0.05$.

\section{Results}

\subsection{The Effect of Zinc Chloride on Blood Glucose and Insulin Levels}

The results of the present study confirmed that administration of STZ in rats showed a significant 3.3-fold increase in serum glucose level and a significant decrease in serum insulin levels to $39 \%$ compared to normal control group, while treatment with Gliclazide restored normal serum levels of glucose and insulin. Similarly, Zinc Chloride significantly decreased the elevated blood glucose levels by $51 \%$ as compared to diabetic control group. In addition, Zinc Chloride administration significantly increased insulin levels to $211 \%$ as compared to STZinduced diabetic rats (Figure 1(a) \& Figure 1(b)).

\subsection{The Effect of Zinc Chloride on Blood Pressure and Heart Rate of STZ-Induced Diabetic Nephropathy in Rats}

Zinc Chloride administration was capable of normalizing the elevated blood pressure in DN rats. Results showed a significant decrease in systolic and diastolic blood pressure, heart rate and mean arterial pressure to 88.6\%, 86.3\%, 95\% and $87.1 \%$ respectively, compared to diabetic control group (Table 1). Similar results were obtained by Gliclazide treatment.

\subsection{The Effect of Zinc Chloride on Renal Function of STZ-Induced Diabetic Nephropathy in Rats}

To explore the effects of Zinc Chloride treatment on renal function, the levels of BUN, serum creatinine, and Albumin were investigated in STZ-induced diabetic rats. Compared with the diabetic control group, Zinc Chloride group showed a significant decrease in BUN and serum creatinine by $21.9 \%$ and $30 \%$ respectively (Figure 2(a) \& Figure 2(b)). On the other hand, Zinc Chloride treated group did not show a significant change in albumin level compared to the DN. 


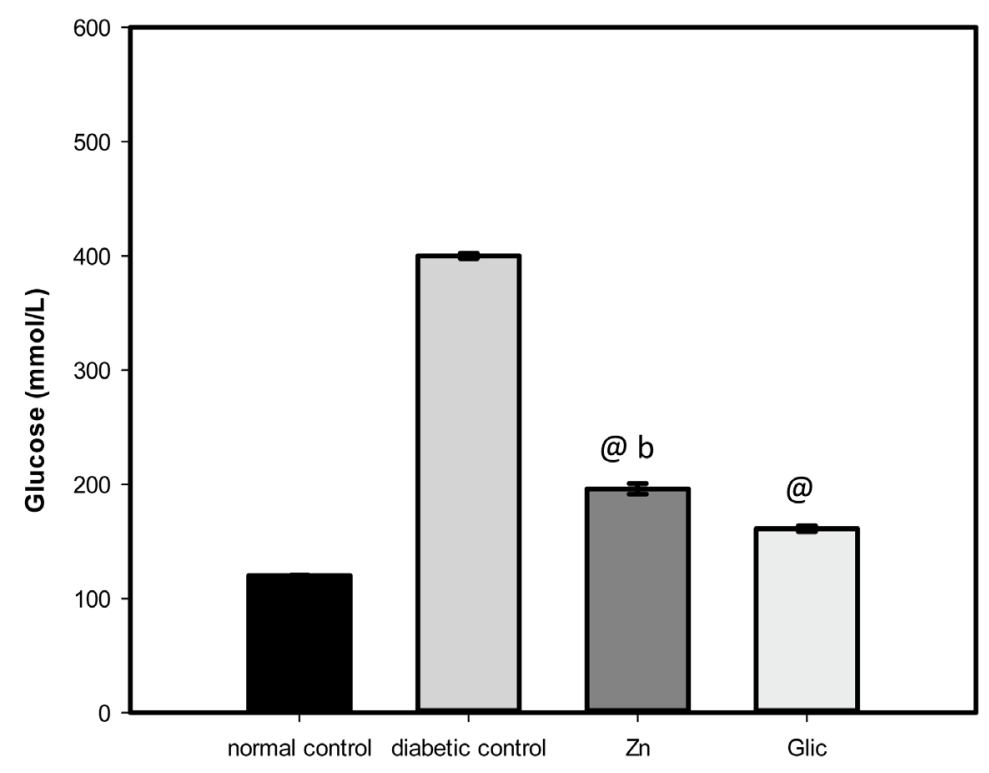

(a)

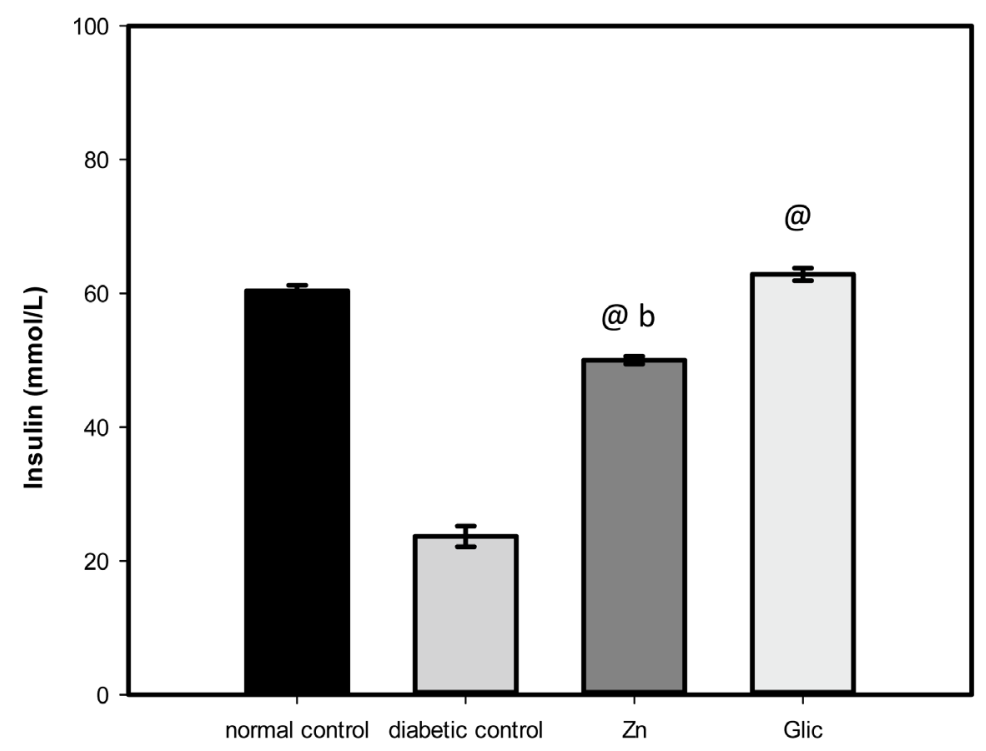

(b)

Figure 1. The effect of Zinc Chloride on blood glucose and insulin levels of STZ-induced diabetic nephropathy in rats. (a) Blood glucose and (b) Insulin. Diabetic nephropathy was induced by a single intraperitoneal injection of STZ dissolved in $0.1 \mathrm{~mol} / \mathrm{L}$ sodium citrate buffer $(\mathrm{pH}=4.0)$ at a dose of $65 \mathrm{mg} / \mathrm{kg}$ body weight, whereas the control group received the same volume of physiological saline. Zinc Chloride group, rats received $5 \mathrm{mg} / \mathrm{kg}$ Zinc Chloride for one month. Data were expressed as mean \pm S.E.M $(n=8)$. @ Significant difference from diabetic control group at $\mathrm{p}<0.05$, bignificant difference from Gliclazide group at $\mathrm{p}<0.05$. Zn; Zinc Chloride, Glic; Gliclazide.

Table 1. The effect of Zinc Chloride administration on the blood pressure and heart rate of STZ-induced diabetic nephropathy in rats.

\begin{tabular}{|c|c|c|c|c|}
\hline & Systolic & Diastolic & HR & MAP \\
\hline Normal control & $151.20 \pm 0.643$ & $137.00 \pm 0.730$ & $396.40 \pm 3.169$ & $141.7 \pm 0.7$ \\
\hline Diabetic control & $174.92 \pm 1.463$ & $152.60 \pm 0.416$ & $368.73 \pm 0.794$ & $160.0 \pm 0.8$ \\
\hline Zinc Chloride & $155.00 \pm 1.713 @$ & $131.67 \pm 1.726 @$ & $350.50 \pm 2.405 @ b$ & 139.4×1.7@ \\
\hline Gliclazide & $154.67 \pm 1.156 @$ & $132.33 \pm 0.715 @$ & $320.67 \pm 1.145 @$ & $139.8 \pm 0.9 @$ \\
\hline
\end{tabular}




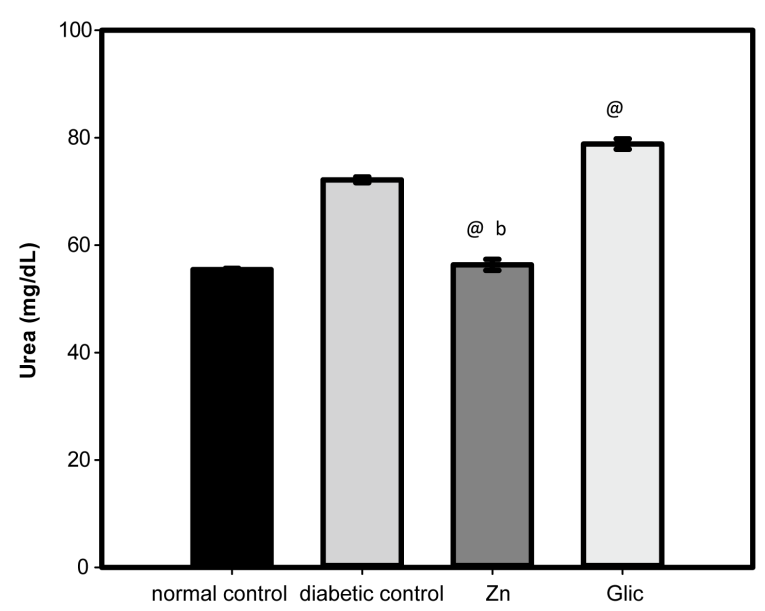

(a)

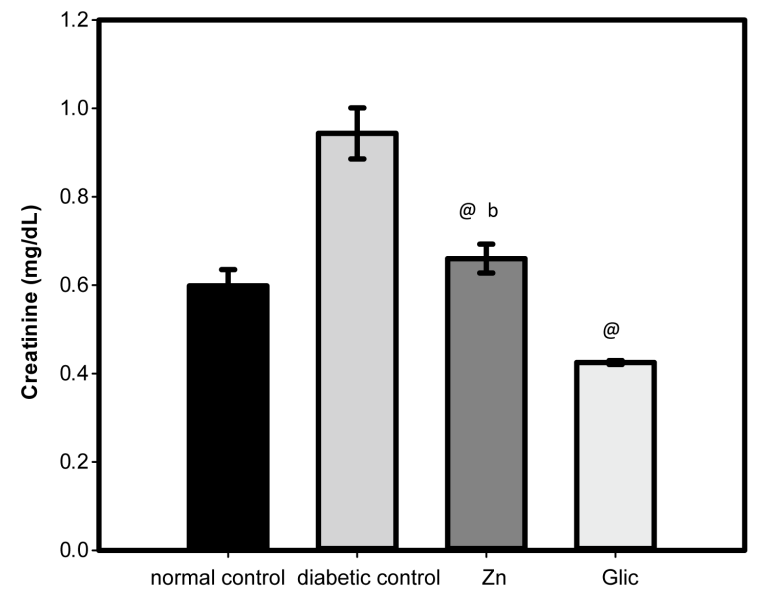

(b)

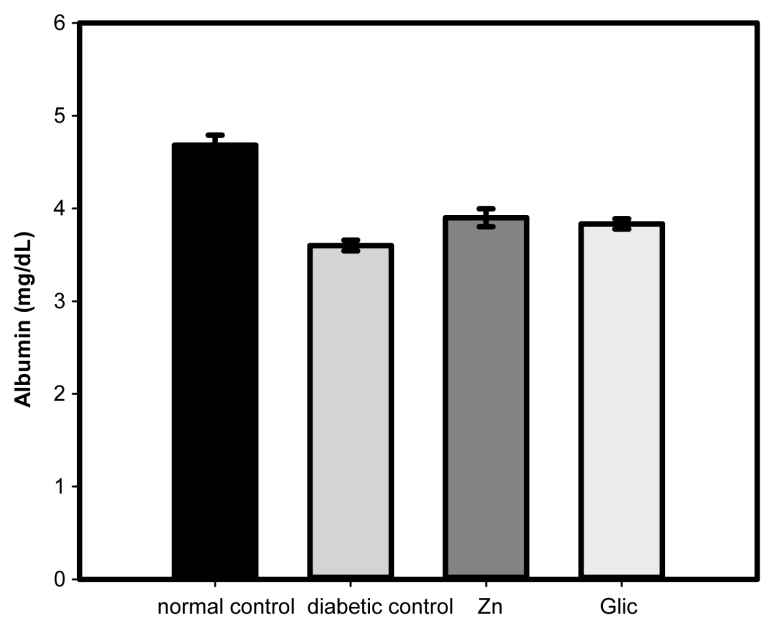

(c)

Figure 2. Zinc Chloride ameliorates kidney functions of STZ-induced diabetic nephropathy in rats. (a) Blood urea nitrogen (BUN). (b) Serum creatinine (sCr). (c) Albumin. Diabetic nephropathy was induced by a single intraperitoneal injection of STZ dissolved in $0.1 \mathrm{~mol} / \mathrm{L}$ sodium citrate buffer $(\mathrm{pH}=4.0)$ at a dose of $65 \mathrm{mg} / \mathrm{kg}$ body weight, whereas the control group received the same volume of physiological saline. Zinc Chloride group, rats, received $5 \mathrm{mg} / \mathrm{kg}$ Zinc Chloride for one month. Data were expressed as mean \pm S.E.M $(n=8)$. ${ }^{@}$ Significant difference from diabetic control group at $\mathrm{p}<0.05$, ${ }^{\mathrm{b}}$ Significant difference from Gliclazide group at $\mathrm{p}<0.05$. Zn; Zinc Chloride, Glic; Gliclazide. 


\subsection{The Effect of Zinc Chloride on Kidney's Oxidative Stress Biomarkers}

In the diabetic control group, STZ evoked oxidative stress and diminished cellular antioxidant capacity, which has been intimately linked to diabetic nephropathy [38]. Oxidative stress was indicated by the elevated levels of MDA (144.4\%) with the concomitant decline of serum GSH (70.5\%) compared to normal control group (Figure 3(a) \& Figure 3(b)). Treatment Gliclazide or Zinc Chloride significantly protected against oxidative stress by the reinstatement of GSH and MDA as compared to diabetic control group.

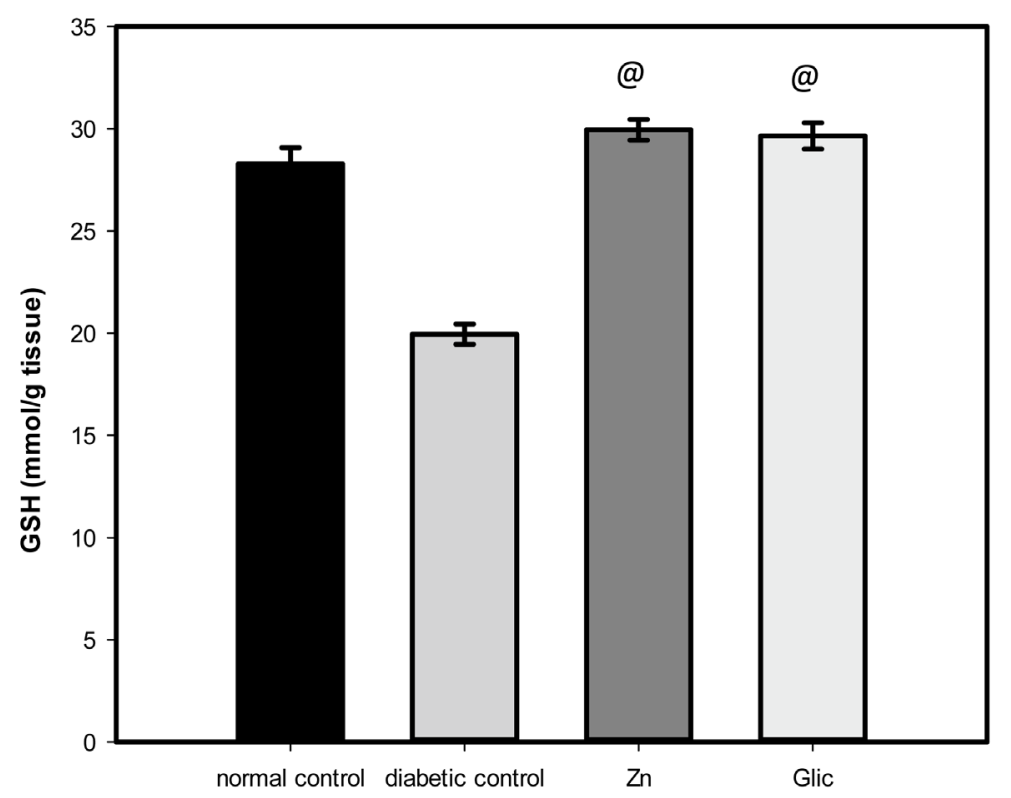

(a)

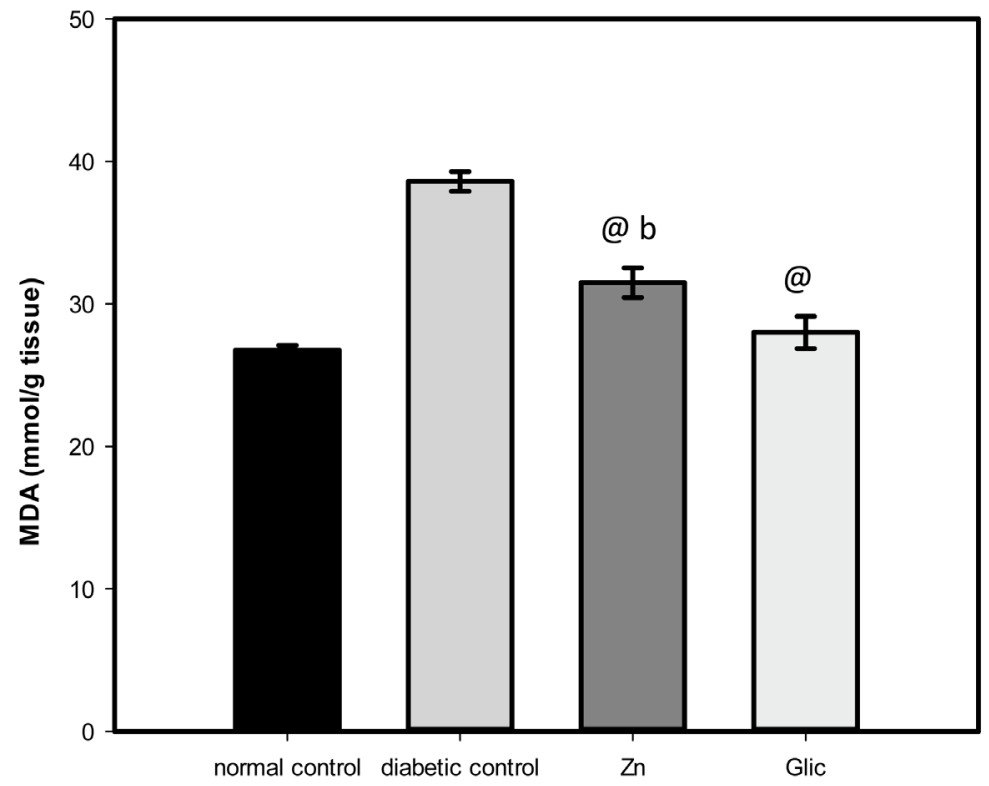

(b)

Figure 3. Zinc Chloride boost antioxidant defenses in rats with STZ-induced diabetic nephropathy. (a) Malondialdehyde; MDA. (b) Reduced glutathione; GSH. Diabetic nephropathy was induced by a single intraperitoneal injection of STZ dissolved in $0.1 \mathrm{~mol} / \mathrm{L}$ sodium citrate buffer $(\mathrm{pH}=4.0)$ at a dose of $65 \mathrm{mg} / \mathrm{kg}$ body weight, whereas the control group received the same volume of physiological saline. Zinc Chloride group, rats, received $5 \mathrm{mg} / \mathrm{kg}$ Zinc Chloride for one month. Data were expressed as mean \pm S.E.M $(n=8)$. ${ }^{@}$ Significant difference from diabetic control group at $\mathrm{p}<0.05$, ${ }^{\mathrm{b}}$ Significant difference from Gliclazide group at $\mathrm{p}<0.05$. Zn; Zinc Chloride, Glic; Gliclazide. 


\subsection{The Effect of Zinc Chloride on Kidney NO Content}

The impact of Zinc Chloride administration on kidney defenses such as NO was also addressed. NO levels were increased in the diabetic control group (149.3\%) as compared to normal control group. Gliclazide or Zinc Chloride were able to restore NO level suggesting their role in attenuation of DN (Figure 4). It was worth noting that Zinc Chloride was more effective than gliclazide in normalizing kidney NO content.

\section{Discussion}

Diabetic nephropathy (DN), as a component of diabetic vascular diseases, worsens most diabetic complications. In particular, the risk of morbidity and mortality from cardiovascular disease is increased several folds [39]. DN is the leading cause of end-stage renal disease (ESRD) in diabetic patients [40]. It affects about $40 \%$ of diabetic patients worldwide. Tight control of glucose level has been reported to reduce both the development and progression of diabetic nephropathy, retinopathy and cardiovascular disease [41] [42]. Agents possessing both hypoglycemic and antioxidant properties were expected to protect against diabetic nephropathy [20].

The findings of the present study indicated that Zinc Chloride blunted the increment in serum glucose, while increased serum insulin levels in diabetic control rats. Consistent with our work, several studies showed the ability of Zinc Chloride to control hyperglycemia [10] [43]. In addition, our results showed a significant increase in the mean arterial blood pressure in the diabetic control rats. These results are in accordance with the observations of Dhein et al. 2000, who reported a marked increase in MAP in diabetic rats [44]. On the other hand, treatment with Gliclazide or Zinc Chloride produced a significant reduction in the elevated MAP, which was in contrast to Moreau et al. 1994, who reported that the glibenclamide-induced blockade of vascular potassium channels caused a vasoconstriction in the systemic and splanchnic vascular beds and hence an increase in blood pressure. [45]. Williams et al. in 1998, reported that night-time systolic blood pressures were significantly higher during glibenclamide treatment than it was with placebo [46]. In addition, Kulkarni et al., in 2002, reported that glibenclamide significantly prevented alloxan-induced hyperglycemia and hypoinsulinemia, but it failed

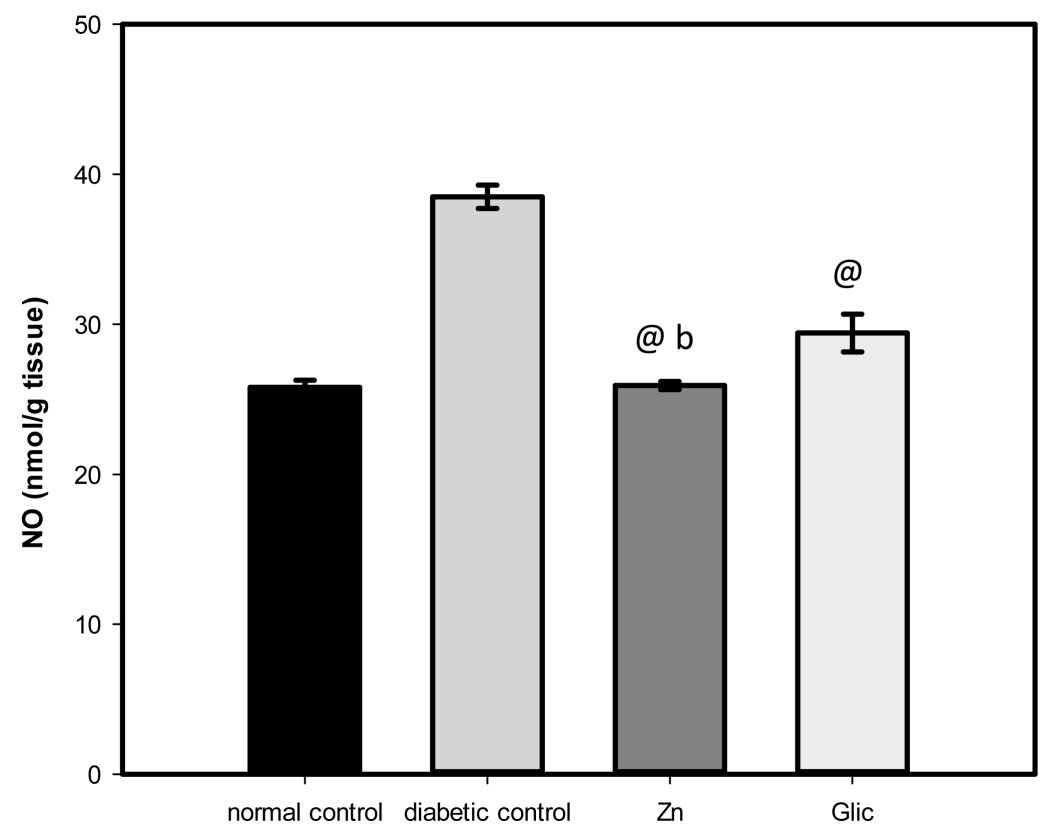

Figure 4. Zinc Chloride restores NO defenses in rats with STZ-induced diabetic nephropathy. Diabetic nephropathy was induced by a single intraperitoneal injection of STZ dissolved in $0.1 \mathrm{~mol} / \mathrm{L}$ sodium citrate buffer $(\mathrm{pH}=4.0)$ at a dose of 65 $\mathrm{mg} / \mathrm{kg}$ body weight, whereas the control group received the same volume of physiological saline. Zinc Chloride group, rats, received $5 \mathrm{mg} / \mathrm{kg}$ Zinc Chloride for one month. Data were expressed as mean \pm S.E.M $(n=8)$. ${ }^{@}$ Significant difference from diabetic control group at $\mathrm{p}<0.05$, 'bignificant difference from Gliclazide group at $\mathrm{p}<0.05$. Zn; Zinc Chloride, Glic; Gliclazide. 
to alter hypertension [47].

Elevated serum levels of urea and creatinine, due to interstitial atrophy and vasodilated atrophic changes in the glomeruli and tubules, have been observed during the progression of diabetes and were known as diabetic nephropathies [48]. Therefore, those were used for the observation of DN's occurrence and progression [49]. An improvement in these abnormal changes is considered direct evidence of an improvement in DN [50]. The present data showed that administration of Zinc Chloride decreased the serum urea and creatinine levels in diabetic rats (Figure 2). Together the data show for the first time the effect of Zinc Chloride in controlling DN.

In our attempt to understand the mechanism underlying the effect of Zinc Chloride in controlling DN, we assessed some of the oxidative stress parameters. Zinc Chloride accentuated serum GSH levels while attenuated the increased levels of MDA and kidney NO, boosting the antioxidant defenses of the kidney. In agreement with the present findings, a study reported the effect of Zinc Chloride on improving MDA and total antioxidant capacity in diabetic rats [27]. Another study also showed the beneficial effects of Zinc Chloride in controlling hyperglycemia thus preserving liver architecture and ameliorating NO, MDA, superoxide dismutase (SOD) and GSH levels [10]. Our results, showing the antioxidant capacity of Zinc Chloride, are in accordance with Li et al., in 2014, who reported the role of Zinc Chloride in preventing renal oxidative damage via upregulation of nuclear factor-erythroid 2-related factor (Nrf2) [43].

\section{Conclusion}

The present study demonstrates for the first time the potential of Zinc Chloride in the management of diabetic nephropathy and suggesting it as a beneficial supplement for diabetic patients. However, further investigations would be required to elucidate fully the mechanisms involved in reducing diabetic nephropathy and intricate interplay among different metabolic pathways.

\section{Acknowledgements}

This work was supported by a research grant number 43410011 from Scientific Research \& Islamic Heritage Institute, Umm Al Qura University, Makkah, Saudi Arabia.

\section{Conflict of Interest Statement}

The authors declare that there are no conflicts of interest.

\section{References}

[1] Shaw, J.E., Sicree, R.A. and Zimmet, P.Z. (2010) Global Estimates of the Prevalence of Diabetes for 2010 and 2030. Diabetes Research and Clinical Practice, 87, 4-14. http://dx.doi.org/10.1016/j.diabres.2009.10.007

[2] Wild, S., et al. (2004) Global Prevalence of Diabetes: Estimates for the Year 2000 and Projections for 2030. Diabetes Care, 27, 1047-1053. http://dx.doi.org/10.2337/diacare.27.5.1047

[3] Elmarakby, A.A. and Sullivan, J.C. (2012) Relationship between Oxidative Stress and Inflammatory Cytokines in Diabetic Nephropathy. Cardiovascular Therapeutics, 30, 49-59. http://dx.doi.org/10.1111/j.1755-5922.2010.00218.x

[4] Shi, Y. and Vanhoutte, P.M. (2009) Reactive Oxygen-Derived Free Radicals Are Key to the Endothelial Dysfunction of Diabetes. Journal of Diabetes, 1, 151-162. http://dx.doi.org/10.1111/j.1753-0407.2009.00030.x

[5] Tiganis, T. (2011) Reactive Oxygen Species and Insulin Resistance: The Good, the Bad and the Ugly. Trends in Pharmacological Sciences, 32, 82-89. http://dx.doi.org/10.1016/j.tips.2010.11.006

[6] Pitocco, D., et al. (2010) Oxidative Stress, Nitric Oxide, and Diabetes. The Review of Diabetic Studies, 7, 15-25. http://dx.doi.org/10.1900/RDS.2010.7.15

[7] Rotruck, J.T., et al. (1973) Selenium: Biochemical Role as a Component of Glutathione Peroxidase. Science, 179, 588-590. http://dx.doi.org/10.1126/science.179.4073.588

[8] Beem, K.M., Richardson, D.C. and Rajagopalan, K.V. (1977) Metal Sites of Copper-Zinc Superoxide Dismutase. Biochemistry, 16, 1930-1936. http://dx.doi.org/10.1021/bi00628a027

[9] Horn Jr., A., et al. (2010) An Iron-Based Cytosolic Catalase and Superoxide Dismutase Mimic Complex. Inorganic Chemistry, 49, 1274-1276. http://dx.doi.org/10.1021/ic901904b

[10] Aly, H.F. and Mantawy, M.M. (2012) Comparative Effects of Zinc, Selenium and Vitamin E or Their Combination on Carbohydrate Metabolizing Enzymes and Oxidative Stress in Streptozotocin Induced-Diabetic Rats. European Review 
for Medical and Pharmacological Sciences, 16, 66-78.

[11] Bonnefont-Rousselot, D., et al. [Diabetes Mellitus, Oxidative Stress and Advanced Glycation Endproducts]. Annales Pharmaceutiques Françaises, 62, 147-157. http://dx.doi.org/10.1016/S0003-4509(04)94297-6

[12] Brownlee, M. (2001) Biochemistry and Molecular Cell Biology of Diabetic Complications. Nature, 414, 813-820. http://dx.doi.org/10.1038/414813a

[13] Susztak, K., et al. (2006) Glucose-Induced Reactive Oxygen Species Cause Apoptosis of Podocytes and Podocyte Depletion at the Onset of Diabetic Nephropathy. Diabetes, 55, 225-233. http://dx.doi.org/10.2337/diabetes.55.01.06.db05-0894

[14] Horie, K., et al. (1997) Immunohistochemical Colocalization of Glycoxidation Products and Lipid Peroxidation Products in Diabetic Renal Glomerular Lesions. Implication for Glycoxidative Stress in the Pathogenesis of Diabetic Nephropathy. Journal of Clinical Investigation, 100, 2995-3004. http://dx.doi.org/10.1172/JCI119853

[15] Dobashi, K., et al. (1991) Effect of Diabetes Mellitus Induced by Streptozotocin on Renal Superoxide Dismutases in the Rat. A Radioimmunoassay and Immunohistochemical Study. Virchows Archiv. B, Cell Pathology including Molecular Pathology, 60, 67-72. http://dx.doi.org/10.1007/BF02899529

[16] Schnackenberg, C.G. and Wilcox, C.S. (2001) The SOD Mimetic Tempol Restores Vasodilation in Afferent Arterioles of Experimental Diabetes. Kidney International, 59, 1859-1864. http://dx.doi.org/10.1046/j.1523-1755.2001.0590051859.x

[17] Melhem, M.F., et al. (2002) Alpha-Lipoic Acid Attenuates Hyperglycemia and Prevents Glomerular Mesangial Matrix Expansion in Diabetes. Journal of the American Society of Nephrology, 13, 108-116.

[18] Melhem, M.F., Craven, P.A. and Derubertis, F.R. (2001) Effects of Dietary Supplementation of Alpha-Lipoic Acid on Early Glomerular Injury in Diabetes Mellitus. Journal of the American Society of Nephrology, 12, 124-133.

[19] Fioretto, P., et al. (1998) Reversal of Lesions of Diabetic Nephropathy after Pancreas Transplantation. The New England Journal of Medicine, 339, 69-75. http://dx.doi.org/10.1056/NEJM199807093390202

[20] Palsamy, P. and Subramanian, S. (2011) Resveratrol Protects Diabetic Kidney by Attenuating Hyperglycemia-Mediated Oxidative Stress and Renal Inflammatory Cytokines via Nrf2-Keap1 Signaling. Biochimica et Biophysica Acta (BBA)—Molecular Basis of Disease, 1812, 719-731. http://dx.doi.org/10.1016/j.bbadis.2011.03.008

[21] Jansen, J., Karges, W. and Rink, L. (2009) Zinc and Diabetes-Clinical Links and Molecular Mechanisms. The Journal of Nutritional Biochemistry, 20, 399-417. http://dx.doi.org/10.1016/j.jnutbio.2009.01.009

[22] Cortese, M.M., Suschek, C.V., Wetzel, W., Kröncke, K.-D. and Kolb-Bachofen, V. (2008) Zinc Protects Endothelial Cells from Hydrogen Peroxide via Nrf2-Dependent Stimulation of Glutathione Biosynthesis. Free Radical Biology and Medicine, 44, 2002-2012. http://dx.doi.org/10.1016/j.freeradbiomed.2008.02.013

[23] Yoon, J.S. (2008) Zinc Status and Dietary Quality of Type 2 Diabetic Patients: Implication of Physical Activity Level. Nutrition Research and Practice, 2, 41-45. http://dx.doi.org/10.4162/nrp.2008.2.1.41

[24] Kazi, T.G., et al. (2008) Copper, Chromium, Manganese, Iron, Nickel, and Zinc Levels in Biological Samples of Diabetes Mellitus Patients. Biological Trace Element Research, 122, 1-18. http://dx.doi.org/10.1007/s12011-007-8062-y

[25] Basaki, M., Saeb, M., Nazifi, S. and Shamsaei, H.A. (2012) Zinc, Copper, Iron, and Chromium Concentrations in Young Patients with Type 2 Diabetes Mellitus. Biological Trace Element Research, 148, 161-164. http://dx.doi.org/10.1007/s12011-012-9360-6

[26] Jansen, J., et al. (2012) Disturbed Zinc Homeostasis in Diabetic Patients by in Vitro and in Vivo Analysis of Insulinomimetic Activity of Zinc. The Journal of Nutritional Biochemistry, 23, 1458-1466. http://dx.doi.org/10.1016/j.jnutbio.2011.09.008

[27] Asri-Rezaei, S., Tamaddonfard, E., Ghasemsoltani-Momtaz, B., Erfanparast, A. and Gholamalipour, S. (2015) Effects of Crocin and Zinc Chloride on Blood Levels of Zinc and Metabolic and Oxidative Parameters in Streptozotocin-Induced Diabetic Rats. Avicenna Journal of Phytomedicine, 5, 403-412.

[28] Sassy-Prigent, C., et al. (1995) Morphometric Detection of Incipient Glomerular Lesions in Diabetic Nephropathy in Rats. Protective Effects of ACE Inhibition. Laboratory Investigation, 73, 64-71.

[29] Tanwar, R.S., Sharma, S.B., Singh, U.R. and Prabhu, K.M. (2010) Attenuation of Renal Dysfunction by Anti-Hyperglycemic Compound Isolated from Fruit Pulp of Eugenia jambolana in Streptozotocin-Induced Diabetic Rats. Indian Journal of Biochemistry \& Biophysics, 47, 83-89.

[30] Hosokawa, M., Dolci, W. and Thorens, B. (2001) Differential Sensitivity of GLUT1- and GLUT2-Expressing Beta Cells to Streptozotocin. Biochemical and Biophysical Research Communications, 289, 1114-1117. http://dx.doi.org/10.1006/bbrc.2001.6145

[31] Friederich, M., Hansell, P. and Palm, F. (2009) Diabetes, Oxidative Stress, Nitric Oxide and Mitochondria Function. Current Diabetes Reviews, 5, 120-144. http://dx.doi.org/10.2174/157339909788166800 
[32] Raza, H., Prabu, S.K., John, A. and Avadhani, N.G. (2011) Impaired Mitochondrial Respiratory Functions and Oxidative Stress in Streptozotocin-Induced Diabetic Rats. International Journal of Molecular Sciences, 12, 3133-3147. http://dx.doi.org/10.3390/ijms12053133

[33] Ezel, T., et al. (2015) Biochemical and Histopathological Investigation of Resveratrol, Gliclazide, and Losartan Protective Effects on Renal Damage in a Diabetic Rat Model. Analytical and Quantitative Cytology and Histology, 37, 187198.

[34] Kumarappan, C.T. and Mandal, S.C. (2008) Polyphenolic Extract of Ichnocarpus frutescens Attenuates Diabetic Complications in Streptozotocin-Treated Diabetic Rats. Renal Failure, 30, 307-322. http://dx.doi.org/10.1080/08860220701857449

[35] Attia, H.N., et al. (2012) Protective Effects of Combined Therapy of Gliclazide with Curcumin in Experimental Diabetic Neuropathy in Rats. Behavioural Pharmacology, 23, 153-161. http://dx.doi.org/10.1097/FBP.0b013e3283512c00

[36] Ohkawa, H., Ohishi, N. and Yagi, K. (1979) Assay for Lipid Peroxides in Animal Tissues by Thiobarbituric Acid Reaction. Analytical Biochemistry, 95, 351-358. http://dx.doi.org/10.1016/0003-2697(79)90738-3

[37] Ellman, G.L. (1959) Tissue Sulfhydryl Groups. Archives of Biochemistry and Biophysics, 82, 70-77. http://dx.doi.org/10.1016/0003-9861(59)90090-6

[38] Park, S.W., et al. (2008) Artemisia asiatica Extracts Protect against Ethanol-Induced Injury in Gastric Mucosa of Rats. Journal of Gastroenterology and Hepatology, 23, 976-984. http://dx.doi.org/10.1111/j.1440-1746.2008.05333.x

[39] Laing, S.P., et al. (2003) Mortality from Heart Disease in a Cohort of 23,000 Patients with Insulin-Treated Diabetes. Diabetologia, 46, 760-765. http://dx.doi.org/10.1007/s00125-003-1116-6

[40] Agarwal, S.K. and Dash, S.C. (2000) Spectrum of Renal Diseases in Indian Adults. The Journal of the Association of Physicians of India, 48, 594-600.

[41] Cefalu, W.T. and Ratner, R.E. (2014) The Diabetes Control and Complications Trial/Epidemiology of Diabetes Interventions and Complications Study at 30 Years: The "Gift" That Keeps on Giving! Diabetes Care, 37, 5-7. http://dx.doi.org/10.2337/dc13-2369

[42] Han, X., Patters, A.B., Ito, T., Azuma, J., Schaffer, S.W. and Chesney, R.W. (2015) Knockout of the TauT Gene Predisposes C57BL/6 Mice to Streptozotocin-Induced Diabetic Nephropathy. PLoS ONE, 10, e0117718. http://dx.doi.org/10.1371/journal.pone.0117718

[43] Li, B., et al. (2014) Zinc Is Essential for the Transcription Function of Nrf2 in Human Renal Tubule Cells in Vitro and Mouse Kidney in Vivo under the Diabetic Condition. Journal of Cellular and Molecular Medicine, 18, 895-906. http://dx.doi.org/10.1111/jcmm.12239

[44] Dhein, S., et al. (2000) Long-Term Effects of the Endothelin(A) Receptor Antagonist LU 135252 and the Angiotensin-Converting Enzyme Inhibitor Trandolapril on Diabetic Angiopathy and Nephropathy in a Chronic Type I Diabetes Mellitus Rat Model. Journal of Pharmacology and Experimental Therapeutics, 293, 351-359.

[45] Moreau, R., et al. (1994) Effects of Glibenclamide on Systemic and Splanchnic Haemodynamics in Conscious Rats. British Journal of Pharmacology, 112, 649-653. http://dx.doi.org/10.1111/j.1476-5381.1994.tb13124.x

[46] Williams, S., et al. (1998) Effects of Glibenclamide on Blood Pressure and Cardiovascular Responsiveness in Non-Insulin Dependent Diabetes Mellitus. Journal of Hypertension, 16, 705-711. http://dx.doi.org/10.1097/00004872-199816050-00019

[47] Kulkarni, J.S., Metha, A.A., Santani, D.D. and Goyal, R.K. (2002) Effects of Chronic Treatment with Cromakalim and Glibenclamide in Alloxan-Induced Diabetic Rats. Pharmacological Research, 46, 101-105. http://dx.doi.org/10.1016/S1043-6618(02)00078-6

[48] Cohen, M.P., Clements, R.S., Cohen, J.A. and Shearman, C.W. (1996) Prevention of Decline in Renal Function in the Diabetic $d b / d b$ Mouse. Diabetologia, 39, 270-274. http://dx.doi.org/10.1007/BF00418341

[49] Montilla, P., et al. (2005) Red Wine Prevents Brain Oxidative Stress and Nephropathy in Streptozotocin-Induced Diabetic Rats. Journal of Biochemistry and Molecular Biology, 38, 539-544. http://dx.doi.org/10.5483/BMBRep.2005.38.5.539

[50] Clark, T.A., et al. (2004) Codelivery of a Tea Extract Prevents Morbidity and Mortality Associated with Oral Vanadate Therapy in Streptozotocin-Induced Diabetic Rats. Metabolism, 53, 1145-1151. http://dx.doi.org/10.1016/j.metabol.2004.03.017 


\section{Abbreviations}

DM: Diabetes mellitus,

DN: Diabetic nephropathy,

GSH: Glutathione,

MDA: Malondialdehyde,

NO: Nitric oxide,

ROS: Reactive oxygen species,

sCR: Serum creatinine.

\section{Submit or recommend next manuscript to SCIRP and we will provide best service for you:}

Accepting pre-submission inquiries through Email, Facebook, LinkedIn, Twitter, etc.

A wide selection of journals (inclusive of 9 subjects, more than 200 journals)

Providing 24-hour high-quality service

User-friendly online submission system

Fair and swift peer-review system

Efficient typesetting and proofreading procedure

Display of the result of downloads and visits, as well as the number of cited articles

Maximum dissemination of your research work

Submit your manuscript at: http://papersubmission.scirp.org/ 